$\underline{\text { Electronic Supplementary Information }}$

\title{
Green Synthesis of Iron Oxides and Phosphates via Thermal \\ Treatment of Iron-Polyphenols Synthesized by Camellia sinensis
}

\section{Extract}

Raissa T. Franco†, Ana Luisa Silva†, ${ }^{a}$ Yordy E. Liceał, Jilder D. P. Sernał, M. Alzamora§, D. R. Sánchezll, Nakédia M. F. Carvalho†*

† Universidade do Estado do Rio de Janeiro, Instituto de Química, Rua São Francisco Xavier, 524, Edifício Haroldo Lisboa da Cunha, IQ, room 312a, Maracanã, 20550-013, Rio de Janeiro, RJ, Brazil.

‡ COMAN/CBPF. Centro Brasileiro de Pesquisas Físicas (CBPF). Rua Dr. Xavier Sigaud, 150, Urca, 22290-180, Rio de Janeiro, RJ, Brazil

§Universidade Federal do Rio de Janeiro, Campus Duque de Caxias, 25265-008 RJ, Brazil

\|I Universidade Federal Fluminense, Instituto de Física, Av. Gal. Milton Tavares de Souza s/nº, Gragoatá, 24210-346, Niterói, RJ, Brasil.

*E-mail: nakedia@uerj.br; Tel: +55 2123340563. 


\section{S.1. Black tea characterization}

Table S1. The total polyphenol concentration (TPCo) determined by the Folin-Ciocalteu method and elemental composition (wt\%) determined by X-ray fluorescence spectrometry, of the black tea leaves.

\begin{tabular}{cc}
\hline TPCo (mgGA/g) & 43.07 \\
$\mathbf{C H} 2$ & 98.6 \\
$\mathbf{K}$ & 0.78 \\
$\mathbf{C a}$ & 0.26 \\
$\mathbf{P}$ & 0.08 \\
$\mathbf{S}$ & 0.07 \\
$\mathbf{M n}$ & 0.06 \\
$\mathbf{F e}$ & 0.005 \\
\hline
\end{tabular}


Caffeine

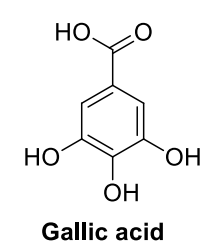

Gallic acid

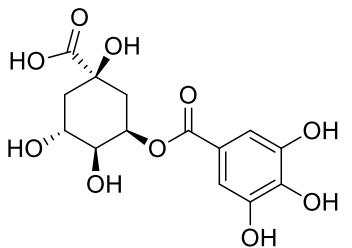

5-galloylquinic acid

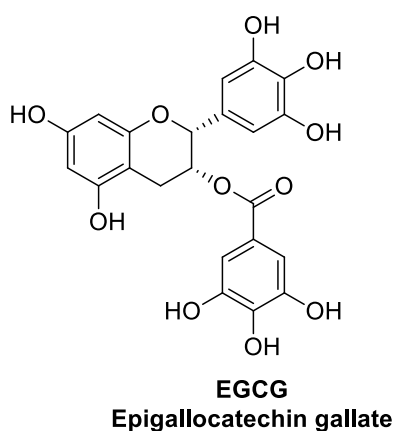<smiles>O=C(/C=C/c1ccc(O)c(O)c1)OC1CC(O)(C(=O)O)C[C@H](O)[C@H]1O</smiles>

5-caffeoylquinic acid<smiles>O=C(O[C@H]1Cc2c(O)cc(O)cc2O[C@H]1c1ccc(O)c(O)c1)c1cc(O)c(O)c(O)c1</smiles>

ECG Epicatechin gallate<smiles>O=C(/C=C/c1ccc(O)cc1)OC1CC(O)(C(=O)O)C[C@H](O)[C@@H]1O</smiles>

4-p-coumaroylquinic acid<smiles>O=c1c(OC2OC(CO)[C@@H](O)[C@H](O)[C@H]2O)c(-c2ccc(O)c(O)c2)oc2cc(O)cc(O)c12</smiles>

Quercetin-3-0-glucoside<smiles>O=c1c(O)cc(C2Oc3cc(O)cc(O)c3C[C@H]2O)cc2c(C3Oc4cc(O)cc(O)c4C[C@H]3O)cc(O)c(O)c12</smiles>

Theaflavin<smiles></smiles><smiles>O=C(O[C@H]1Cc2c(O)cc(O)cc2OC1c1cc(O)c(=O)c2c(O)c(O)cc(C3Oc4cc(O)cc(O)c4C[C@H]3OC(=O)c3cc(O)c(O)c(O)c3)c2c1)c1cc(O)c(O)c(O)c1</smiles>

Theaflavin-3,3'-digallate

Scheme S1. Structures of the major phenolics and purine alkaloids found in teas. Adapted with permission from (reference [1]: D. Del Rio, A. J. Stewart, W. Mullen, J. Burns, M. E. J. Lean, F. Brighenti, A. Crozier. HPLC-MSn Analysis of Phenolic Compounds and Purine Alkaloids in Green and Black Tea. J. Agric. Food Chem. 2004, 52, 2807-2815). Copyright (C) 2004, American Chemical Society.

[1] D. Del Rio, A. J. Stewart, W. Mullen, J. Burns, M. E. J. Lean, F. Brighenti, A. Crozier. HPLCMSn Analysis of Phenolic Compounds and Purine Alkaloids in Green and Black Tea. J. Agric. Food Chem. 2004, 52, 2807-2815.

[2] Shiming Li, Chih-Yu Lo, Min-Hsiung Pan, Ching-Shu Lai, Chi-Tang Ho. Black tea: chemical analysis and stability. Food Funct., 2013, 4, 10-18; DOI: 10.1039/c2fo30093a.

[3] Diky Ramdani, Abdul S. Chaudhry, Chris J. Seal. Alkaloid and polyphenol analysis by HPLC in green and black tea powders and their potential use as additives in ruminant diets. AIP Conference Proceedings 1927, 030008 (2018); https://doi.org/10.1063/1.5021201. 


\section{S.2. Iron nanoparticles characterization}

\section{S.2.1. X-ray diffraction}

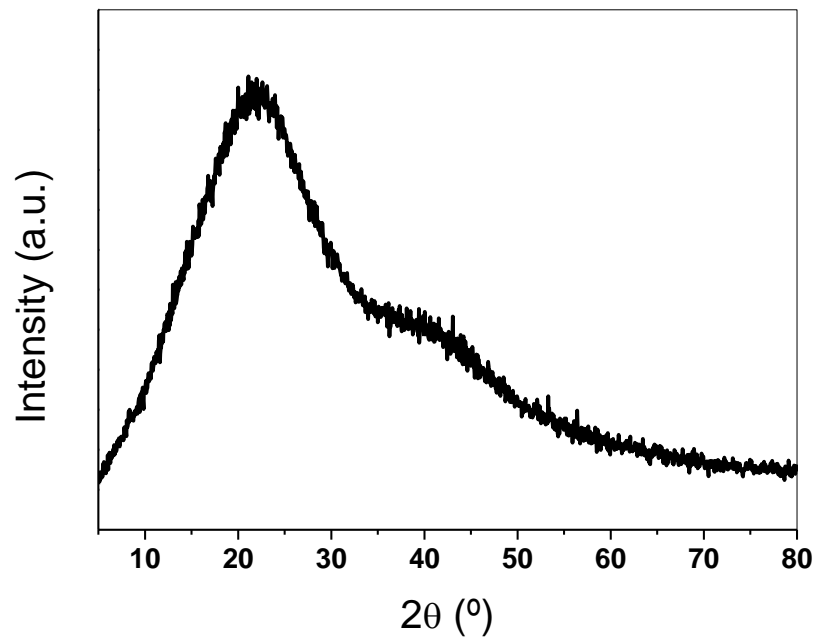

Figure S1. X-Ray Diffraction (XRD) patterns of the as-prepared ${ }^{\mathbf{B T}} \mathbf{F e}$.

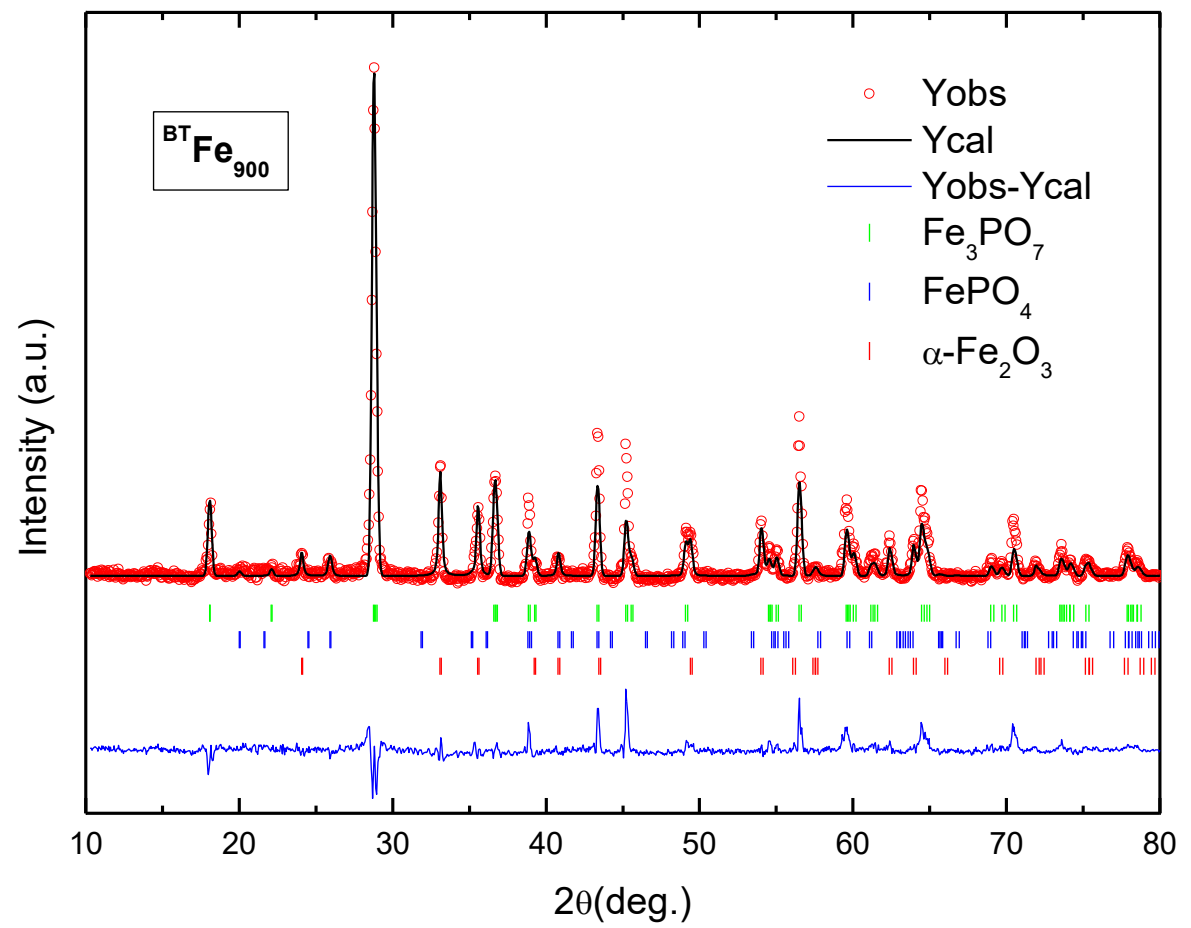

Figure S2. Rietveld refinement of the X-ray diffraction pattern of ${ }^{\text {BT4 }} \mathbf{F e}$ 900 catalyst. The experimental data are represented by open red circles and the calculated pattern by the black solid lines. The difference pattern (Yobs-Ycalc) is given by the solid blue line at bottom of the figure. The vertical green bars shows the positions of the Bragg reflections of each phase. 


\section{S.2.2. Thermogravimetric analysis}

Table S2. Weight loss (wt \%) in dry basis in relation to the degradation temperature, determined by thermogravimetric analysis for ${ }^{\mathbf{B T}} \mathbf{F e}$.

\begin{tabular}{l|cccccc}
\hline \multicolumn{1}{r|}{ Temperature $\left({ }^{\mathbf{0}} \mathbf{C}\right)$} & $\mathbf{4 0 0}$ & $\mathbf{5 0 0}$ & $\mathbf{6 0 0}$ & $\mathbf{7 0 0}$ & $\mathbf{8 0 0}$ & $\mathbf{9 0 0}$ \\
& & & & & & \\
\hline Atmosphere & 30.4 & 39.8 & 46.6 & 52.0 & 56.4 & 59.1 \\
\hline Sitrogen & & & & & & \\
\hline
\end{tabular}

\section{S.2.3. SEM}
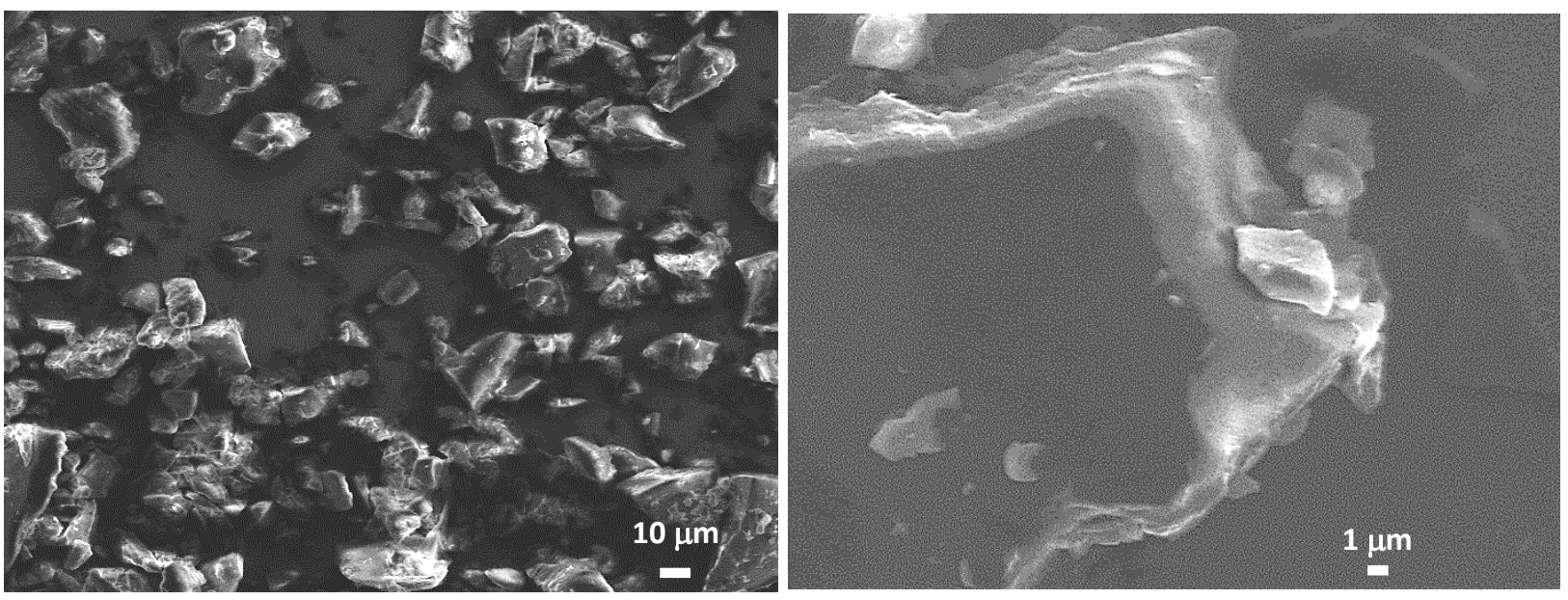

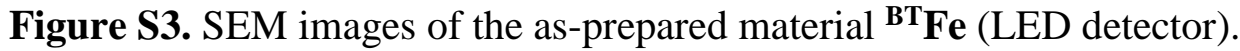



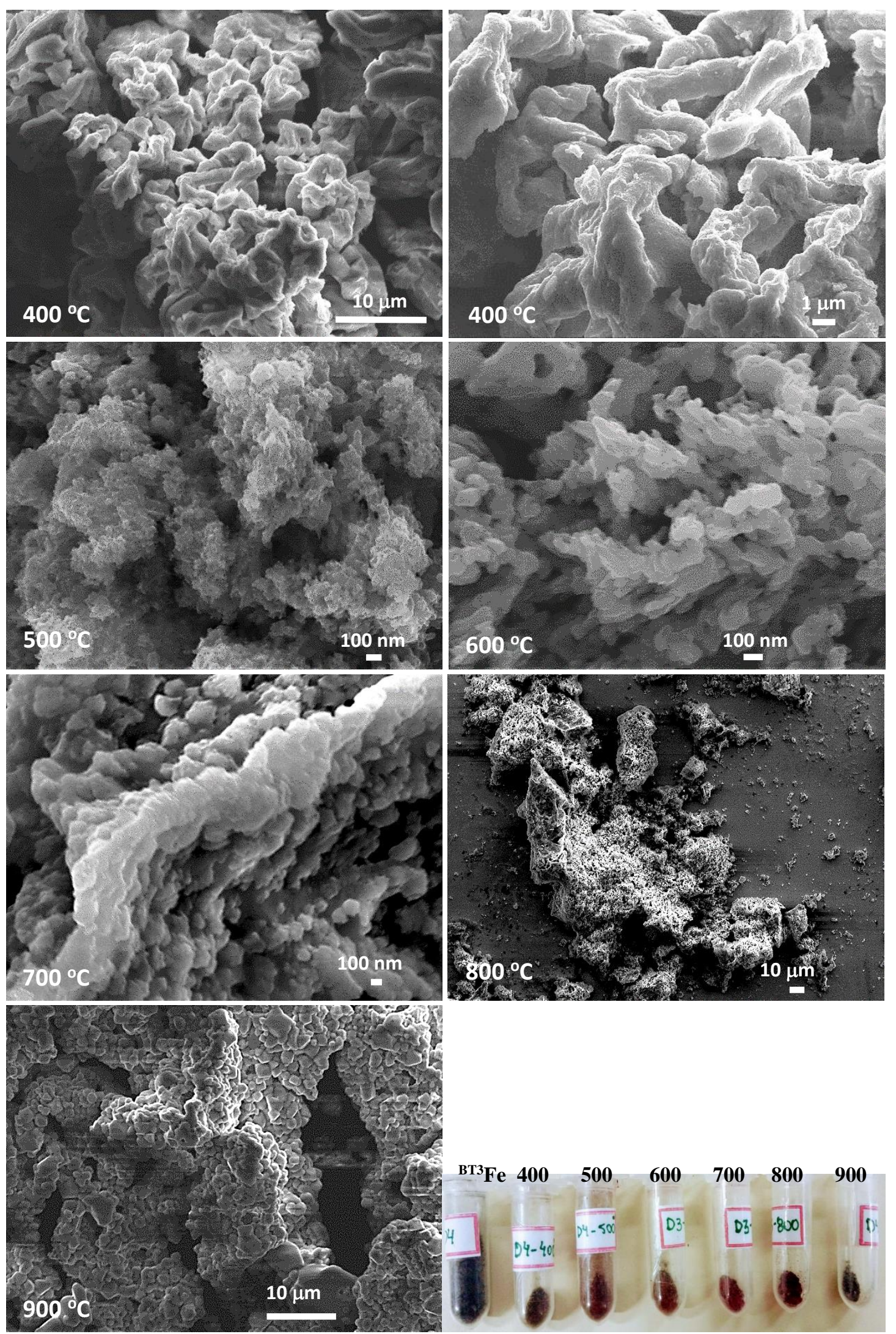

Figure S4. SEM images of the calcinated samples ${ }^{\mathbf{B T}} \mathbf{F e}_{\mathbf{T}}$ at different temperatures. 

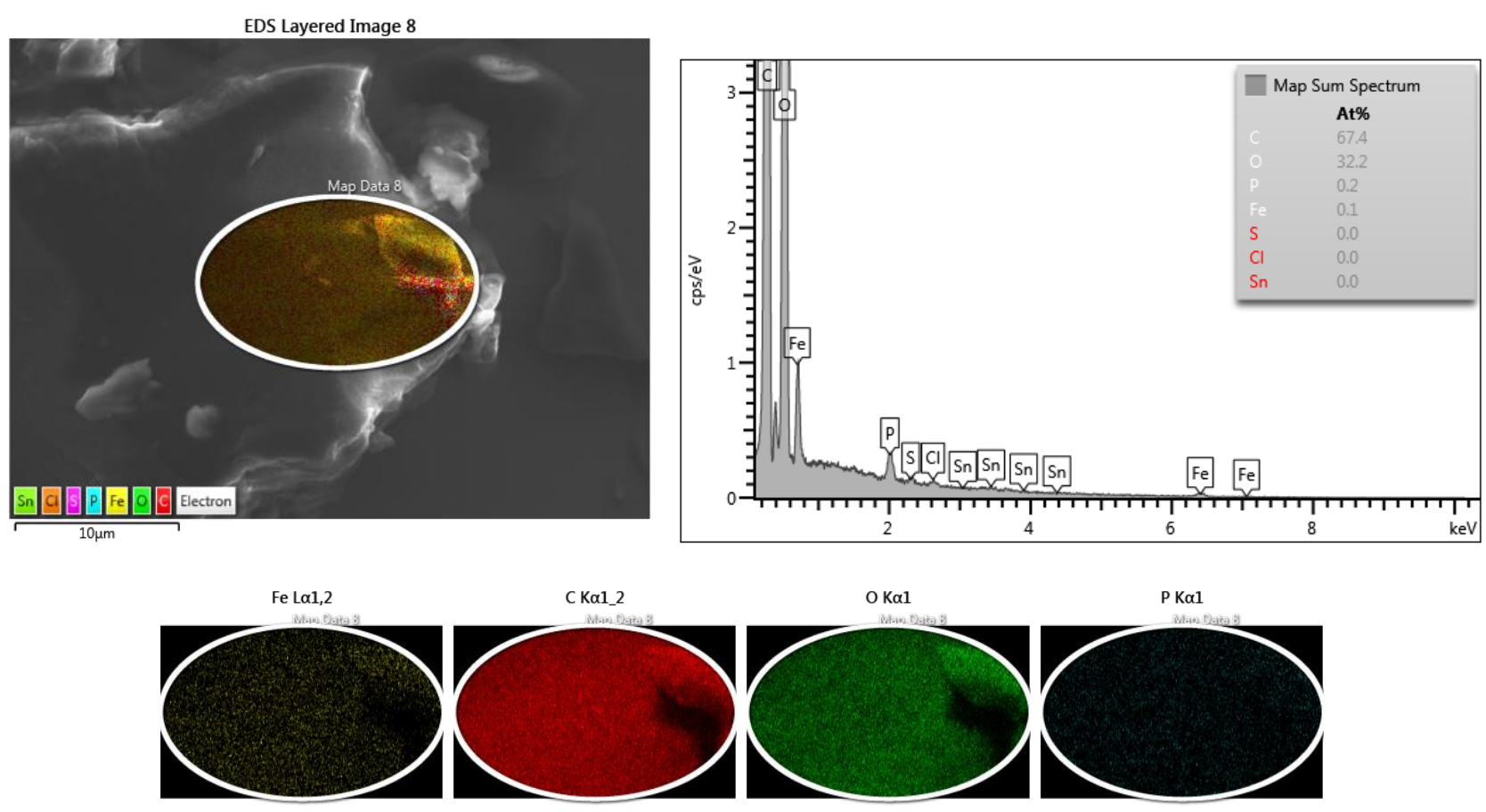

5um

5um

5um

5um

Figure S5. SEM-EDS spectrum and element mapping of the as-prepared ${ }^{\mathbf{B T}} \mathbf{F e}$. 

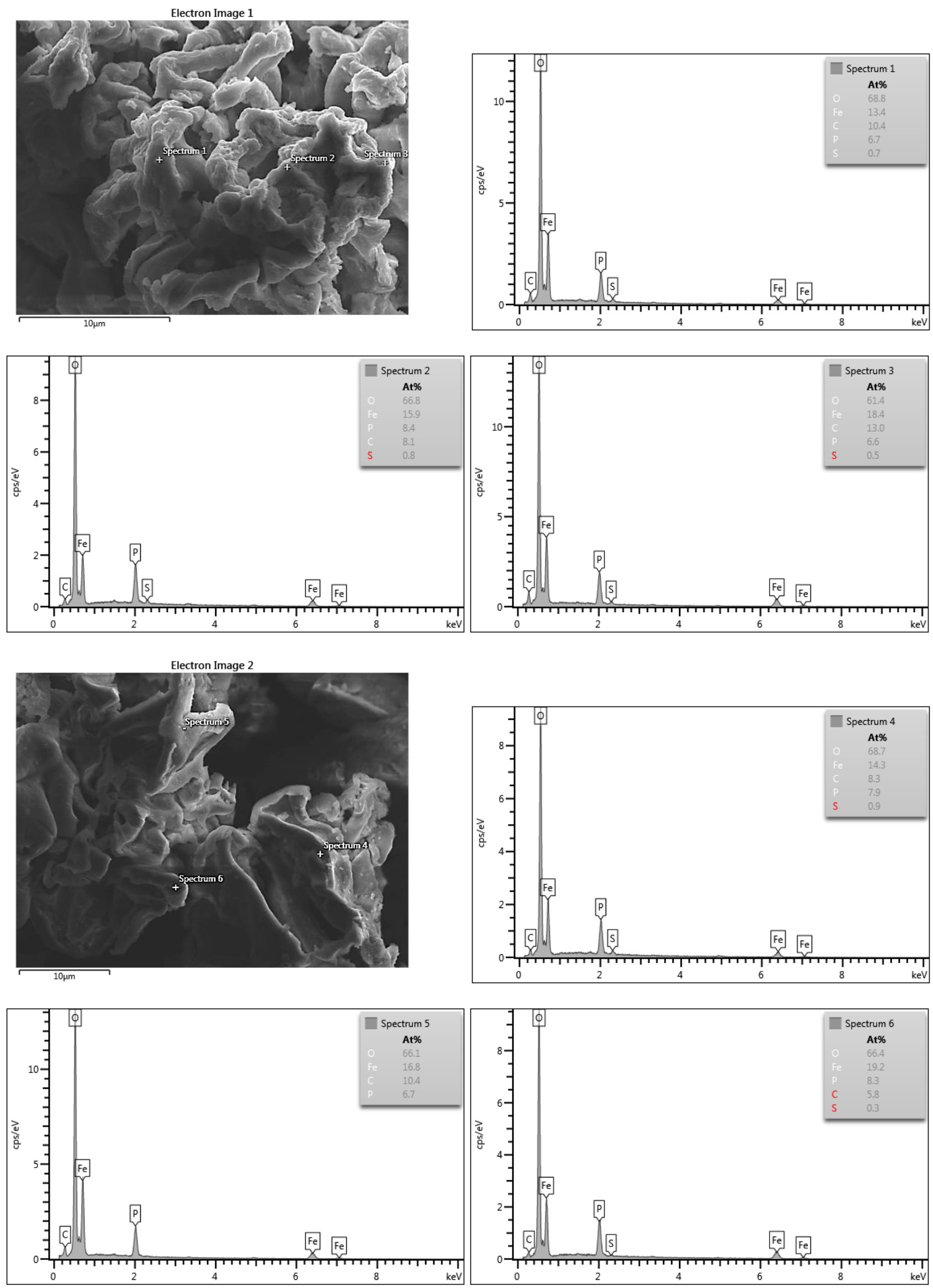

Figure S6. SEM-EDS spectra of ${ }^{\mathbf{B T}} \mathbf{F e} 400$. 

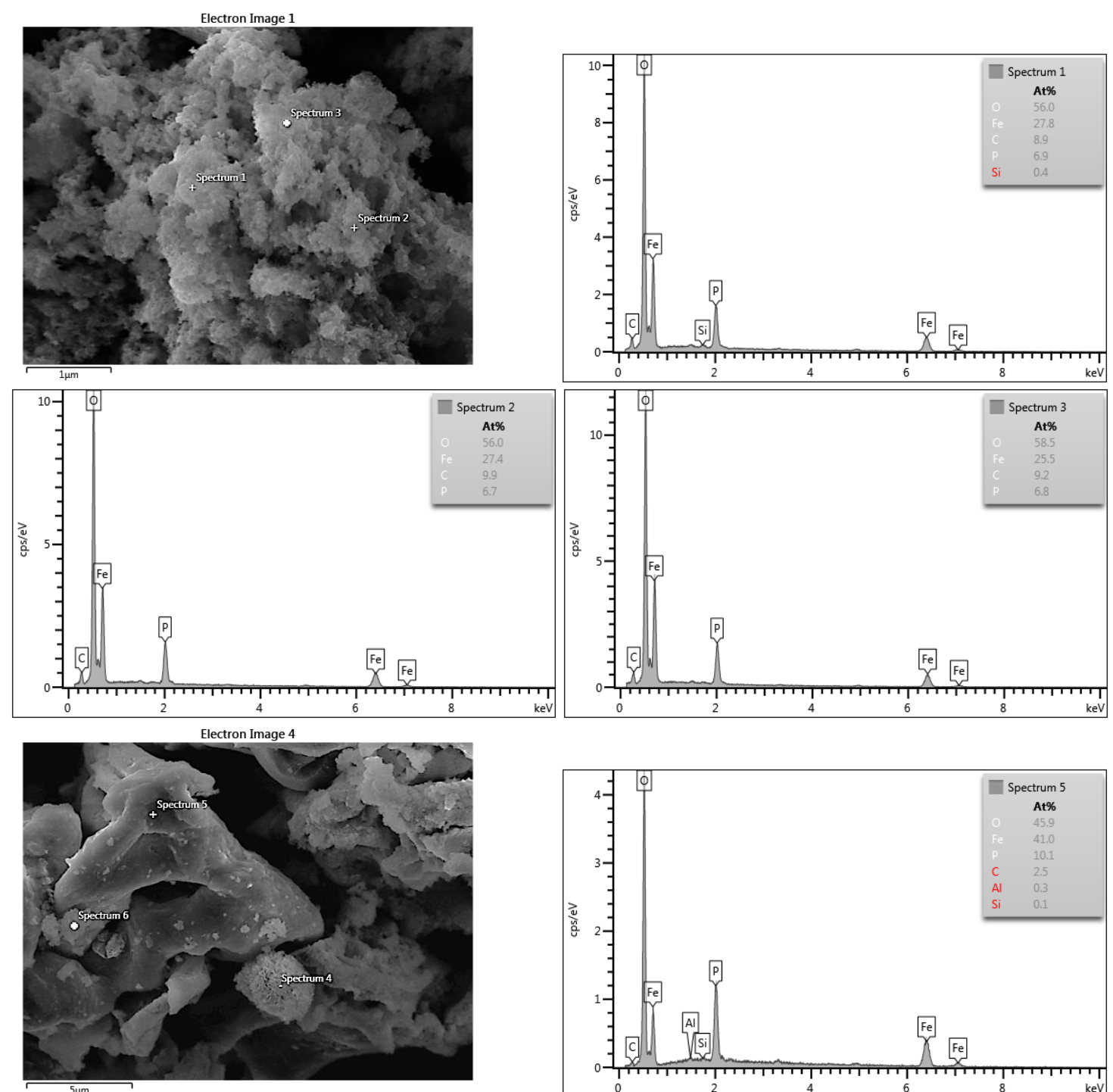

Electron Image 3
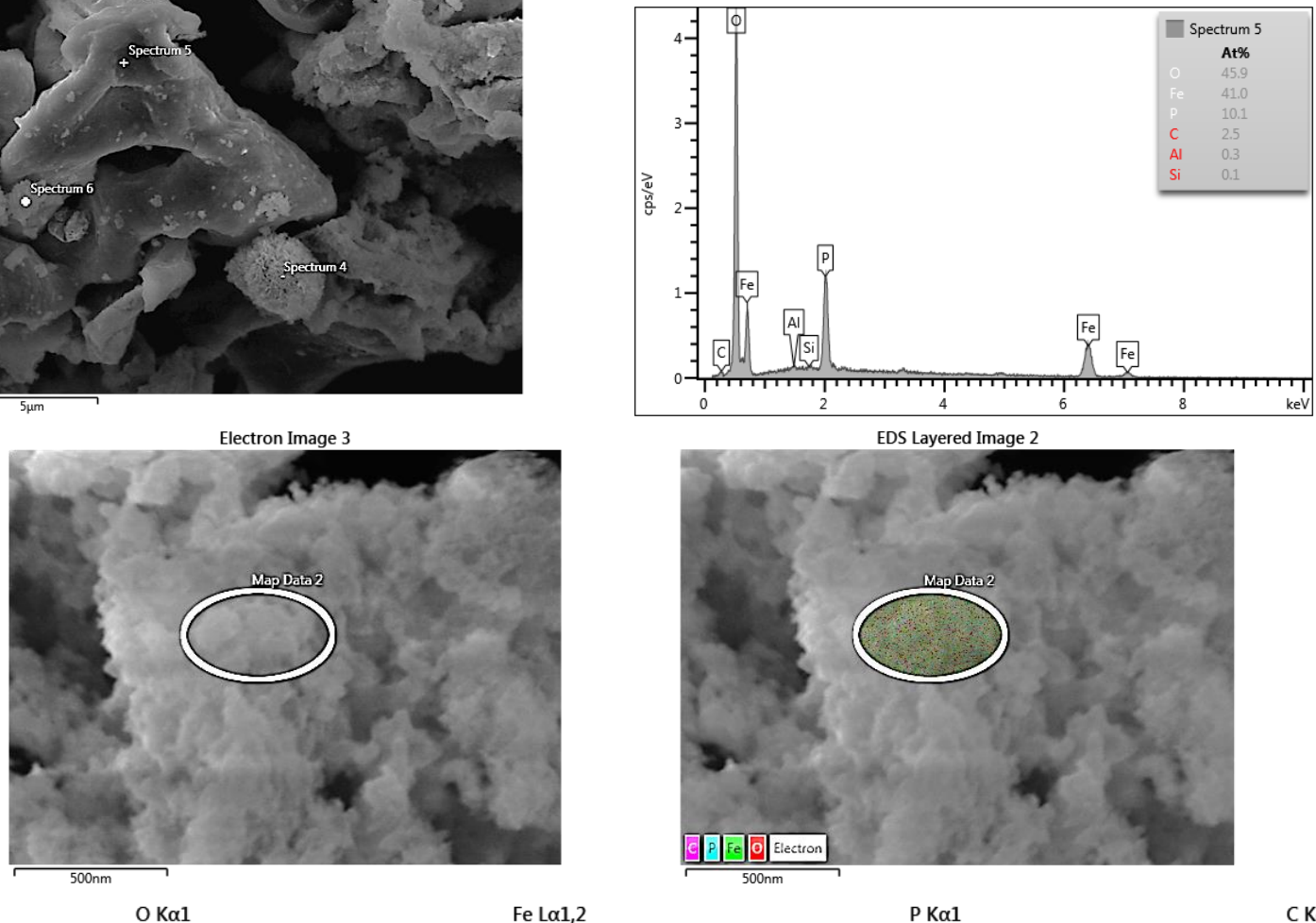
EDS Layered Image 2

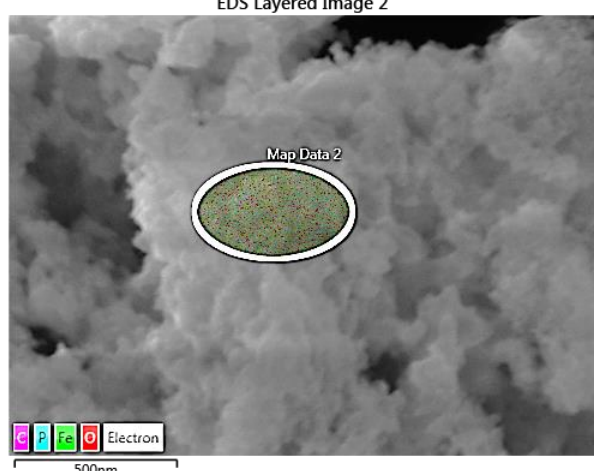

$\mathrm{P} \mathrm{K \alpha 1}$

C K $\alpha 1 \_2$

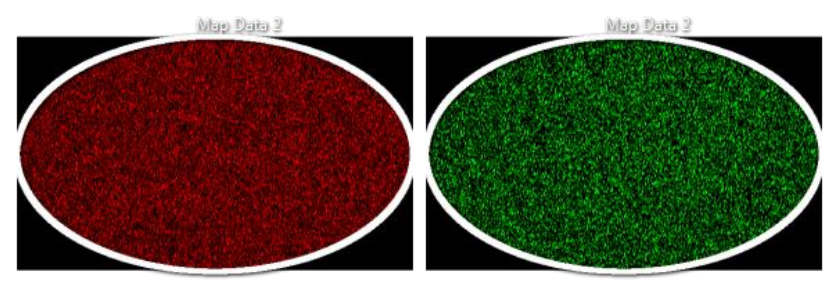

Mite Dero 3
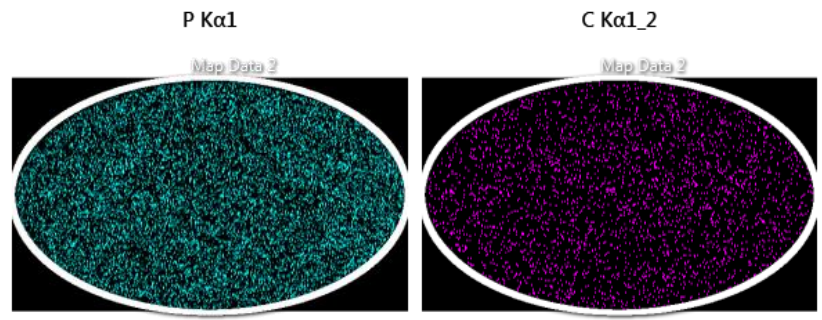

Figure S7. SEM-EDS spectrum and element mapping of ${ }^{\mathbf{B T}} \mathbf{F e} \mathbf{5 0 0}$. 
Electron Image 1
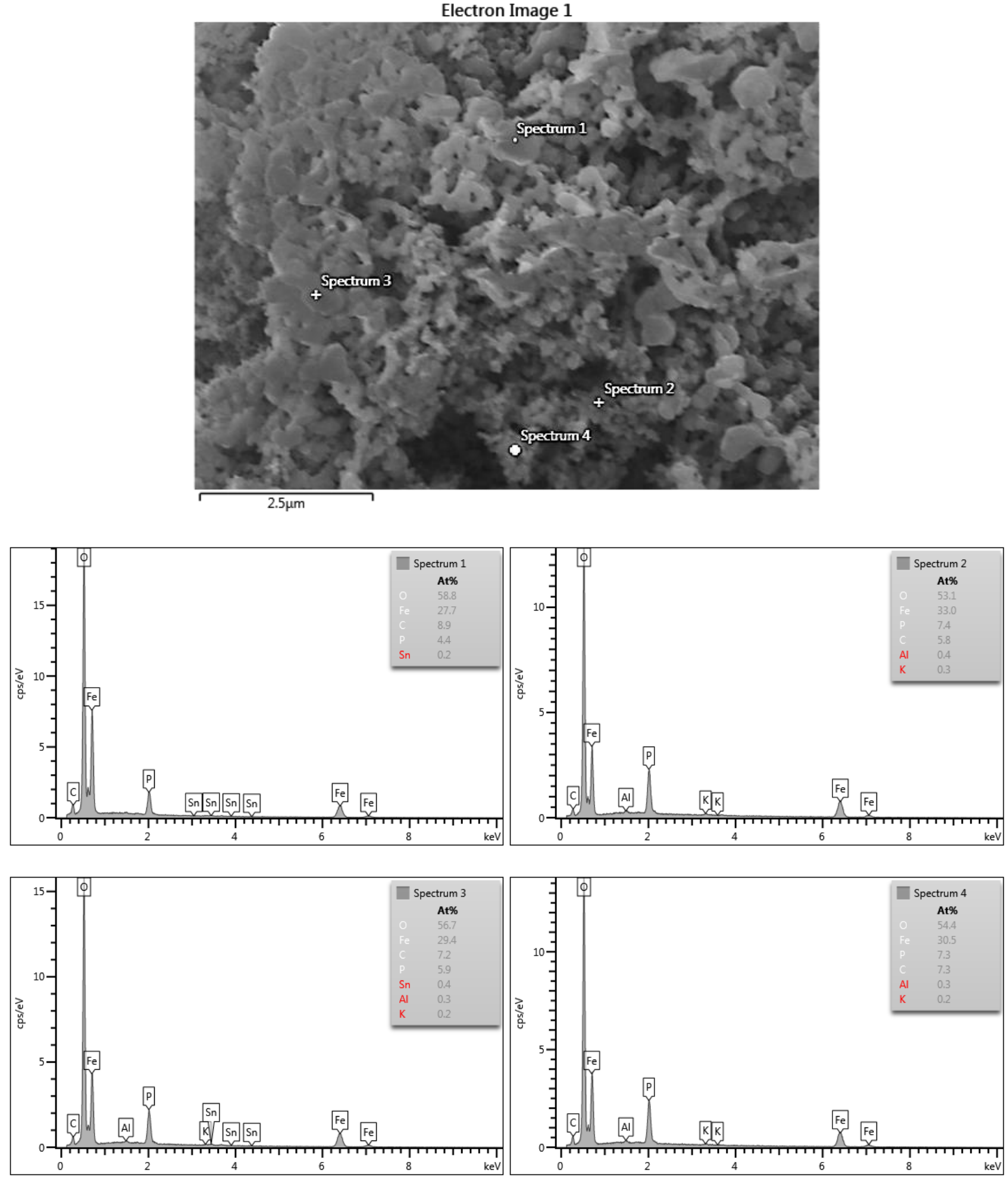
Electron Image 2
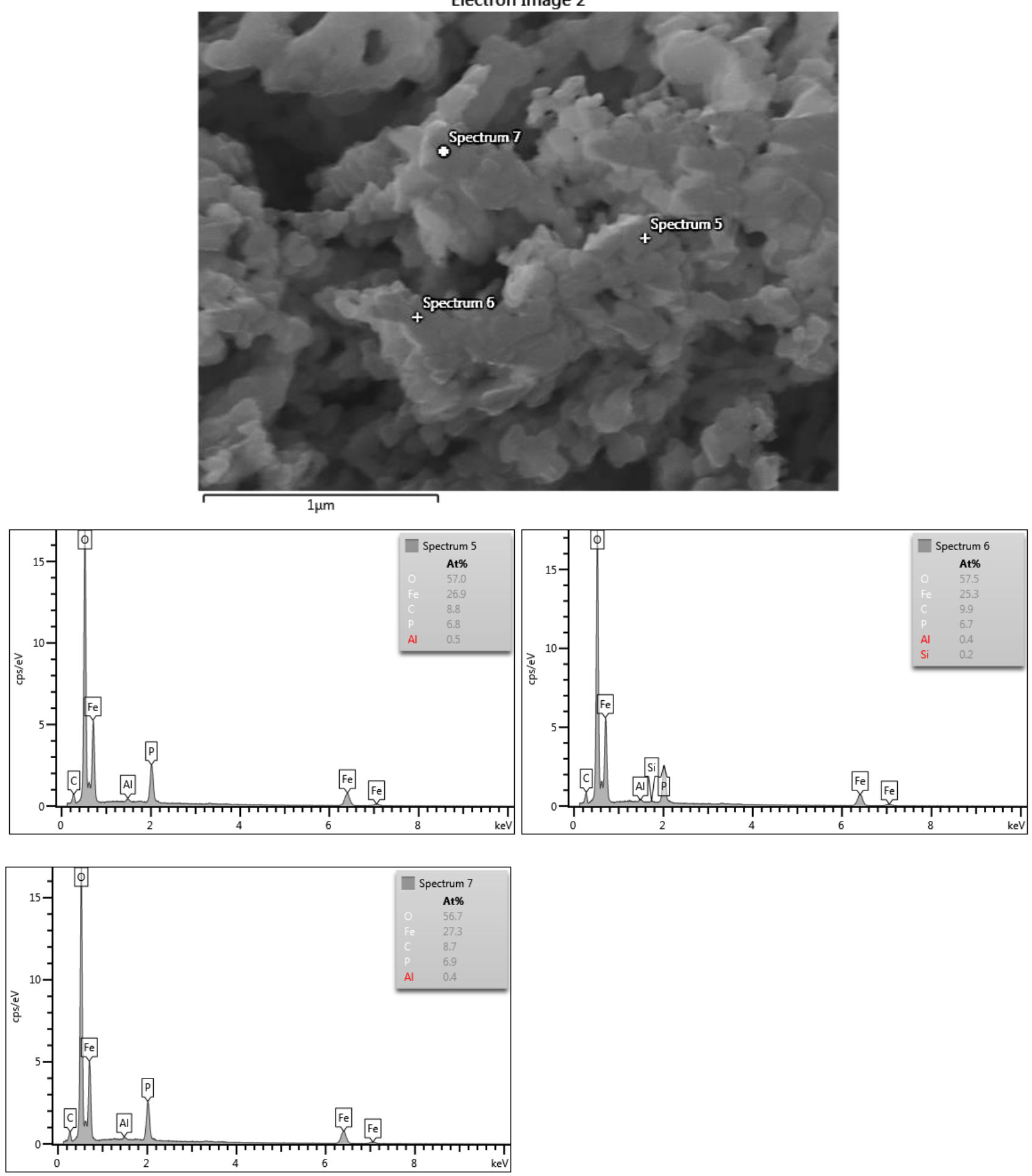

Figure S8. SEM-EDS spectra of ${ }^{\mathbf{B T}} \mathbf{F e} 600$. 

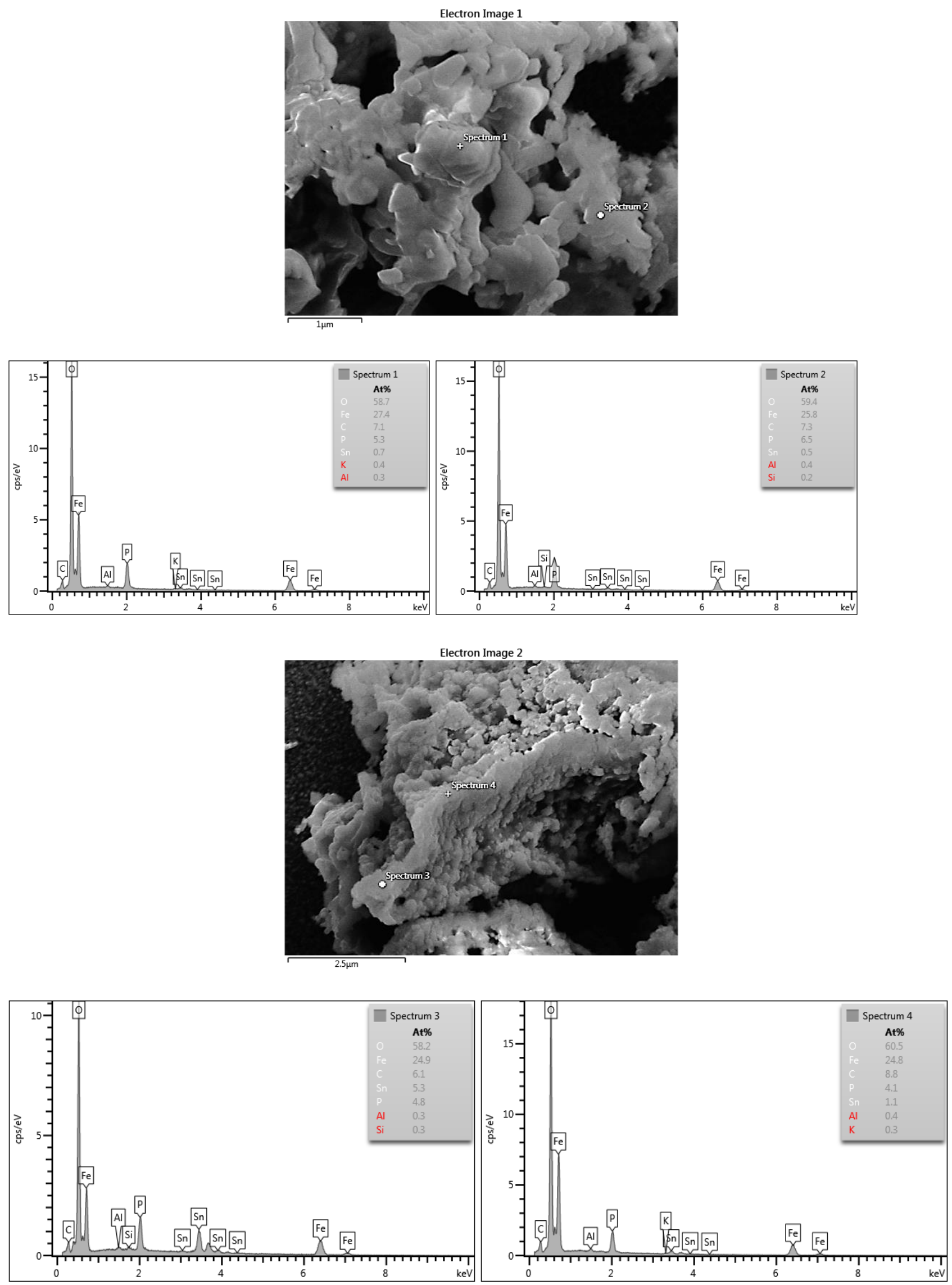

Figure S9. SEM-EDS spectra of ${ }^{\mathbf{B T}} \mathbf{F e} 700$. 

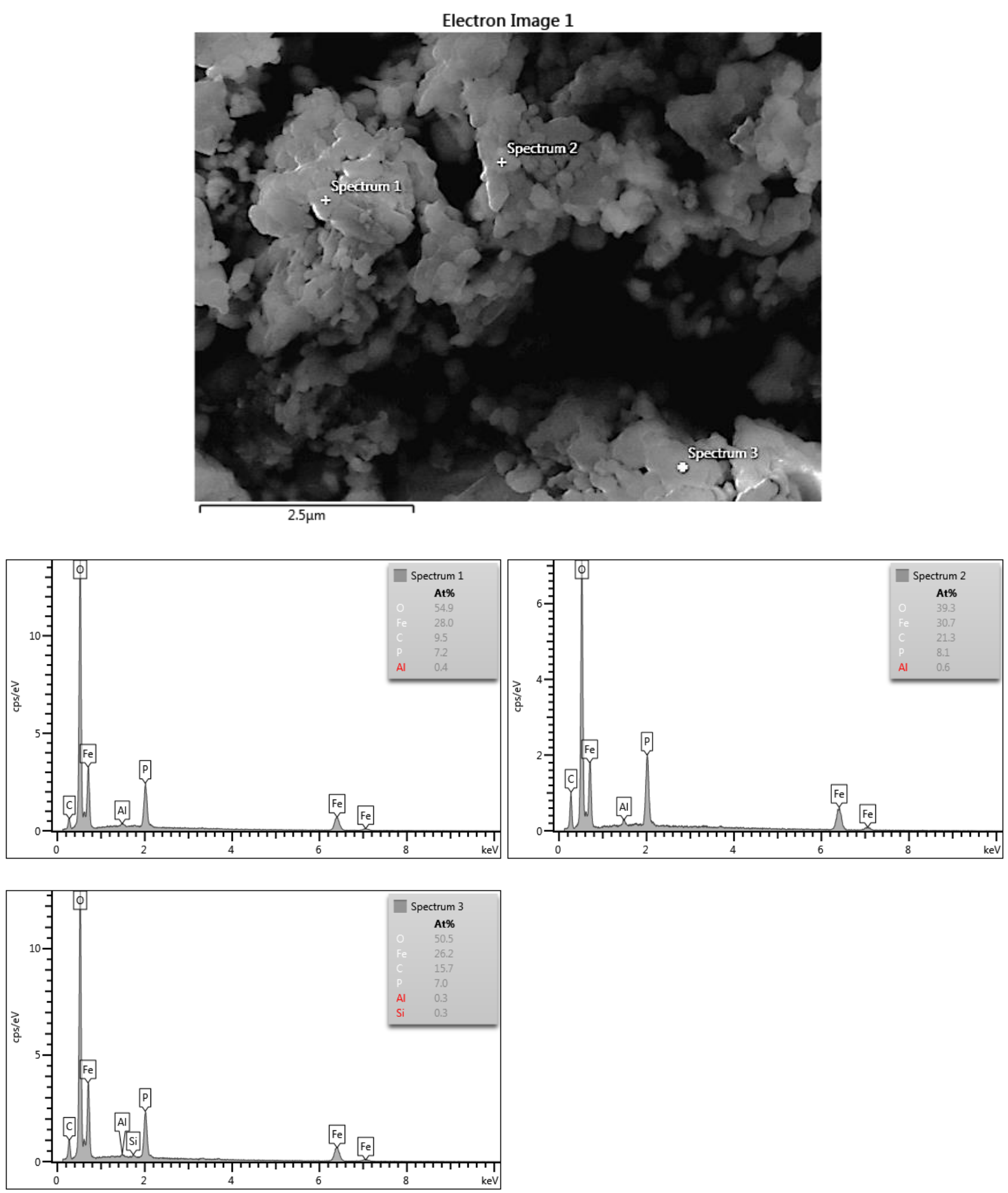

Figure S10. SEM-EDS spectra of ${ }^{\mathbf{B T}} \mathbf{F e} \mathbf{8 0 0}$. 


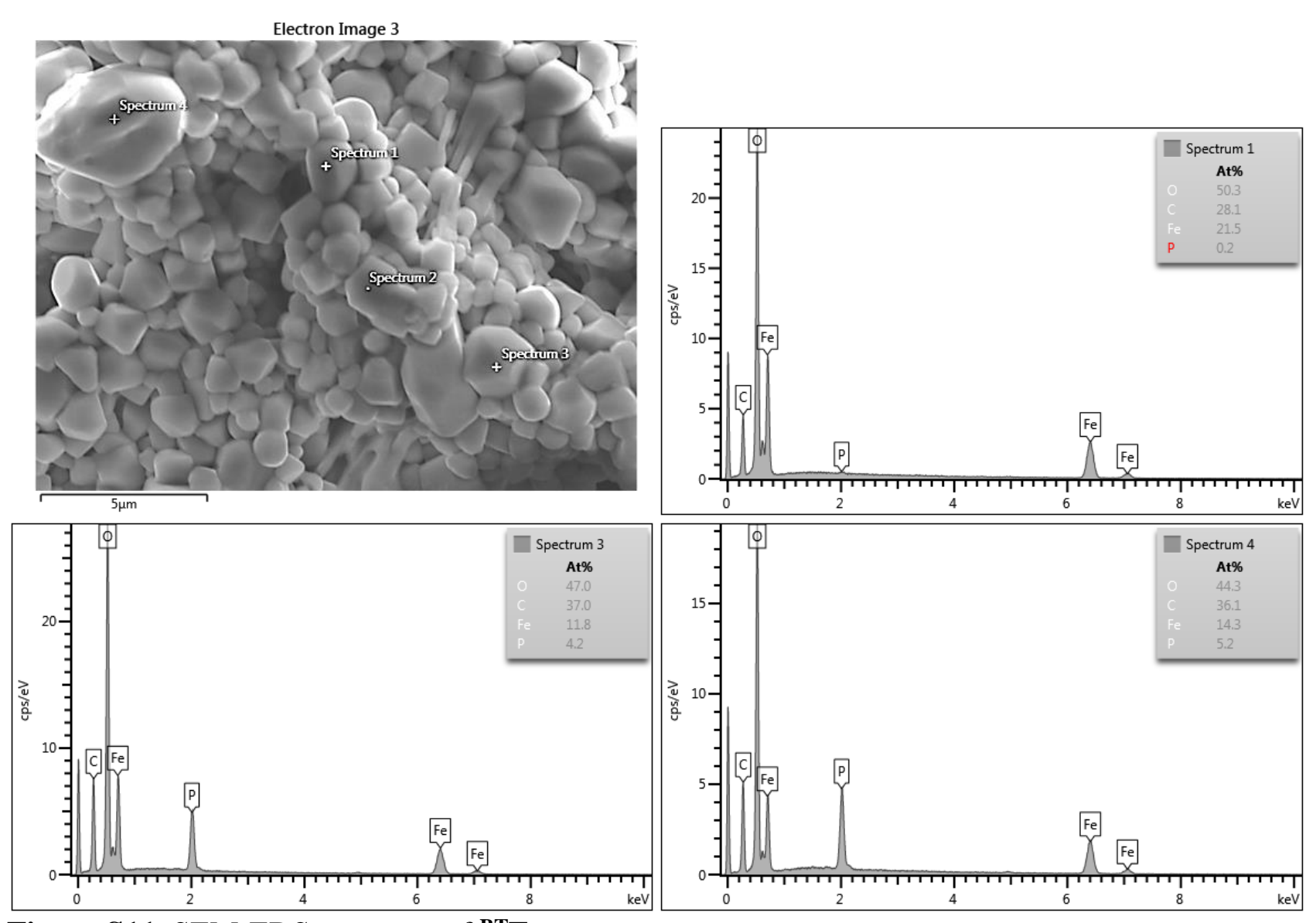

Figure S11. SEM-EDS spectrum of ${ }^{\mathbf{B} T} \mathbf{F e 9 0 0}$. 


\section{S.2.4. TEM}

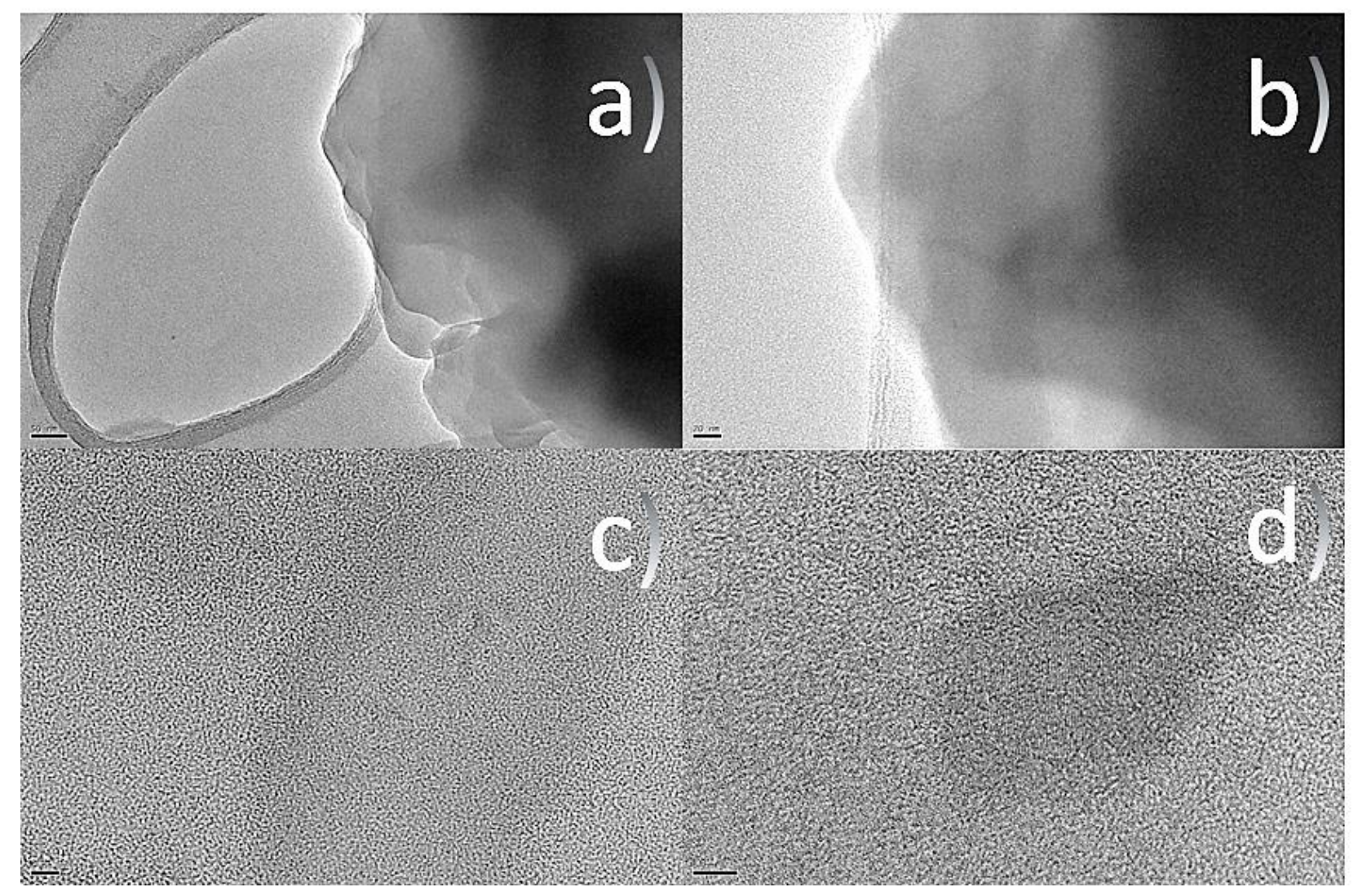

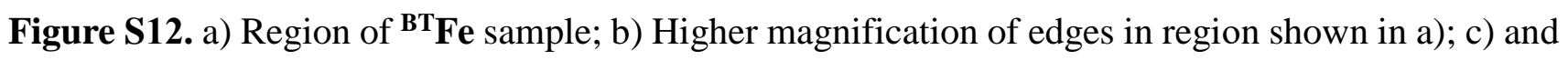
d) show two inspected regions in the sample where NPs at high-resolution appeared (see Figure S13 and S14 below). 


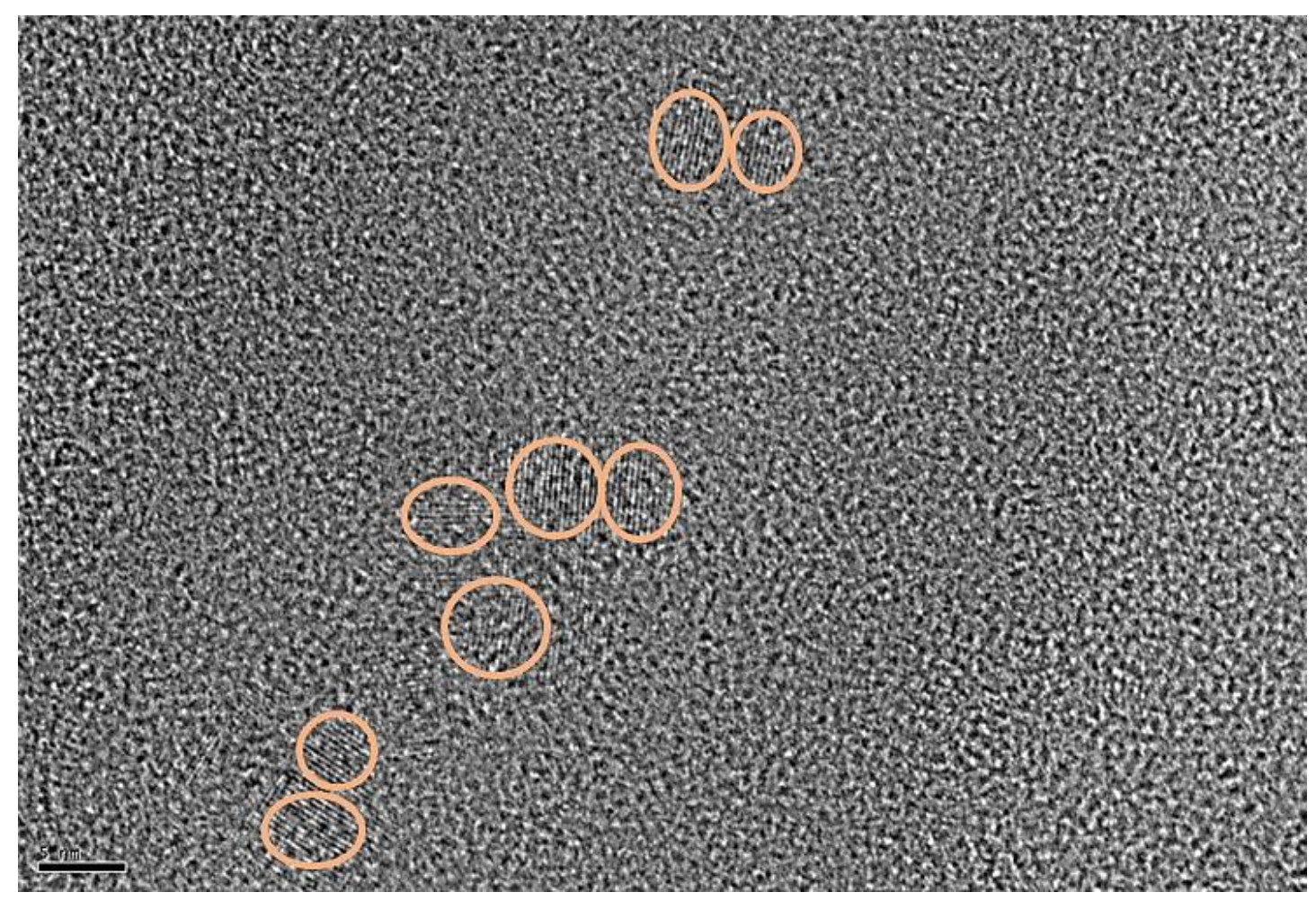

Figure S13. HR-TEM image of region in Figure S12c). NPs are limited by orange circles to facilitate their visualization. Black line scale $(5 \mathrm{~nm})$.

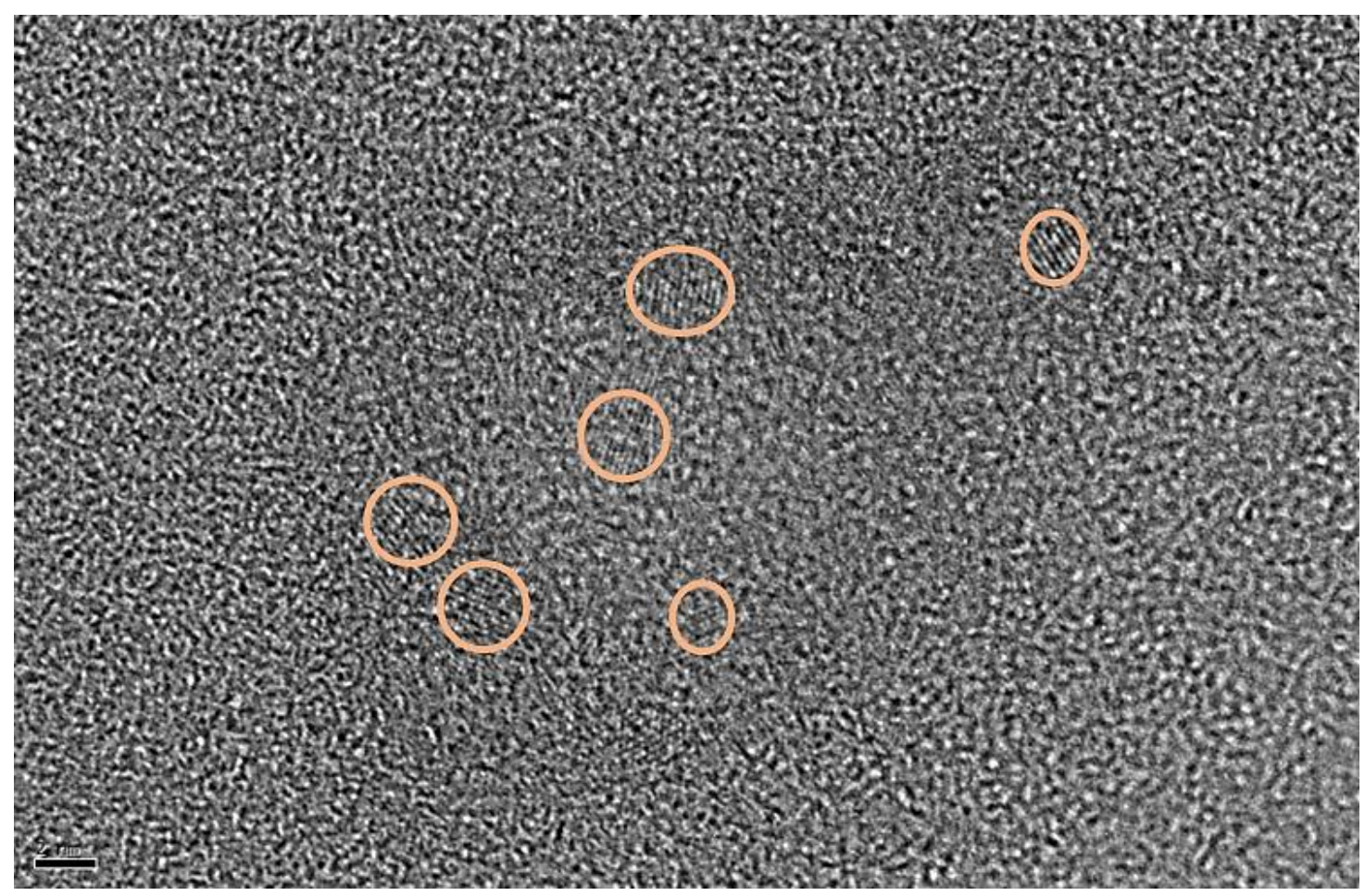

Figure S14. HR-TEM image of region in Figure S12d). NPs are limited by orange circles to facilitate their visualization. Black line scale $(2 \mathrm{~nm})$. 

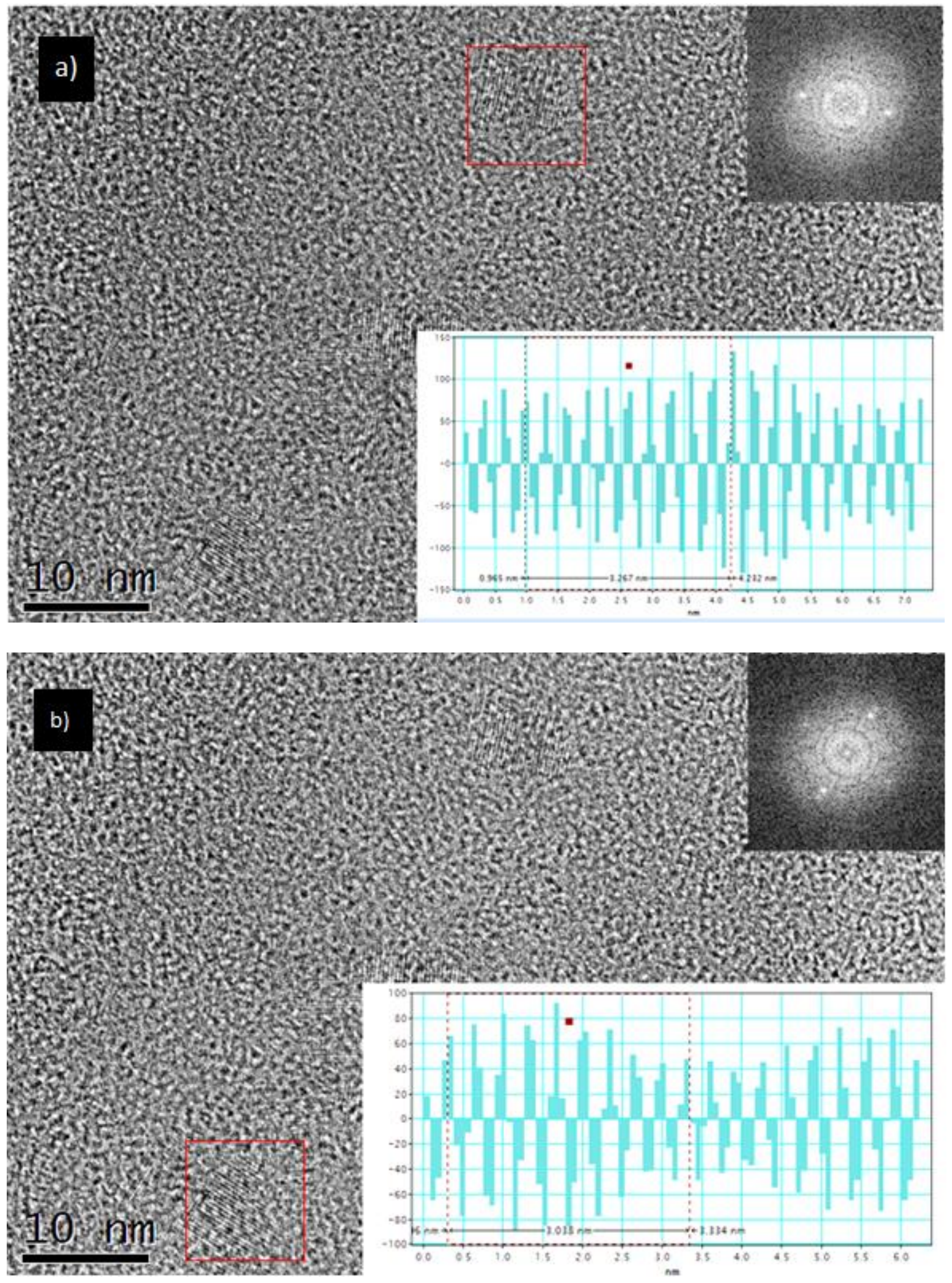

Figure S15. HR-TEM image of two, (a) and (b), selected regions in image Figure S12(d). Their corresponding FT of red squared area and inverse FT profile (of the masked FT two most intensive points) are shown as insets. 


\section{S.2.5. EPR}

Table S3. Parameters obtained from the fitting of EPR spectra at room temperature, the peak-to-peak amplitude $A_{p p}$, the resonant field $H_{r}$ and the peak-to-peak line width $\Delta H_{p p}$.

\begin{tabular}{|c|c|c|c|c|c|c|}
\hline Sample & $A_{p p 1}$ & $H_{r 1}(\mathrm{mT})$ & $\Delta H_{p p 1}(\mathrm{mT})$ & $A_{p p 2}$ & $H_{r 2}(\mathrm{mT})$ & $\Delta H_{p p 2}(\mathrm{mT})$ \\
\hline As-prepared & $1197 \pm 7$ & $344.9 \pm 0.2$ & $91.4 \pm 0.6$ & $196 \pm 10$ & $167.5 \pm 0.6$ & $35.3 \pm 1.2$ \\
\hline 400 & $2445 \pm 12$ & $317.0 \pm 0.2$ & $113.9 \pm 0.4$ & - & - & - \\
\hline 500 & $32318 \pm 93$ & $321.4 \pm 0.2$ & $135.0 \pm 0.3$ & - & - & - \\
\hline 600 & $41453 \pm 67$ & $306.2 \pm 0.1$ & $181.5 \pm 0.2$ & - & - & - \\
\hline 700 & $7248 \pm 19$ & $348.9 \pm 0.1$ & $17.8 \pm 0.1$ & $1003 \pm 5$ & $312.5 \pm 0.3$ & $179.9 \pm 0.6$ \\
\hline 800 & $4123 \pm 10$ & $348.7 \pm 0.1$ & $16.3 \pm 0.1$ & $678 \pm 4$ & $325.0 \pm 0.2$ & $75.6 \pm 0.3$ \\
\hline 900 & $59930 \pm 319$ & $348.9 \pm 0.1$ & $16.1 \pm 0.1$ & $15224 \pm 106$ & $319.4 \pm 0.3$ & $99.3 \pm 0.5$ \\
\hline
\end{tabular}

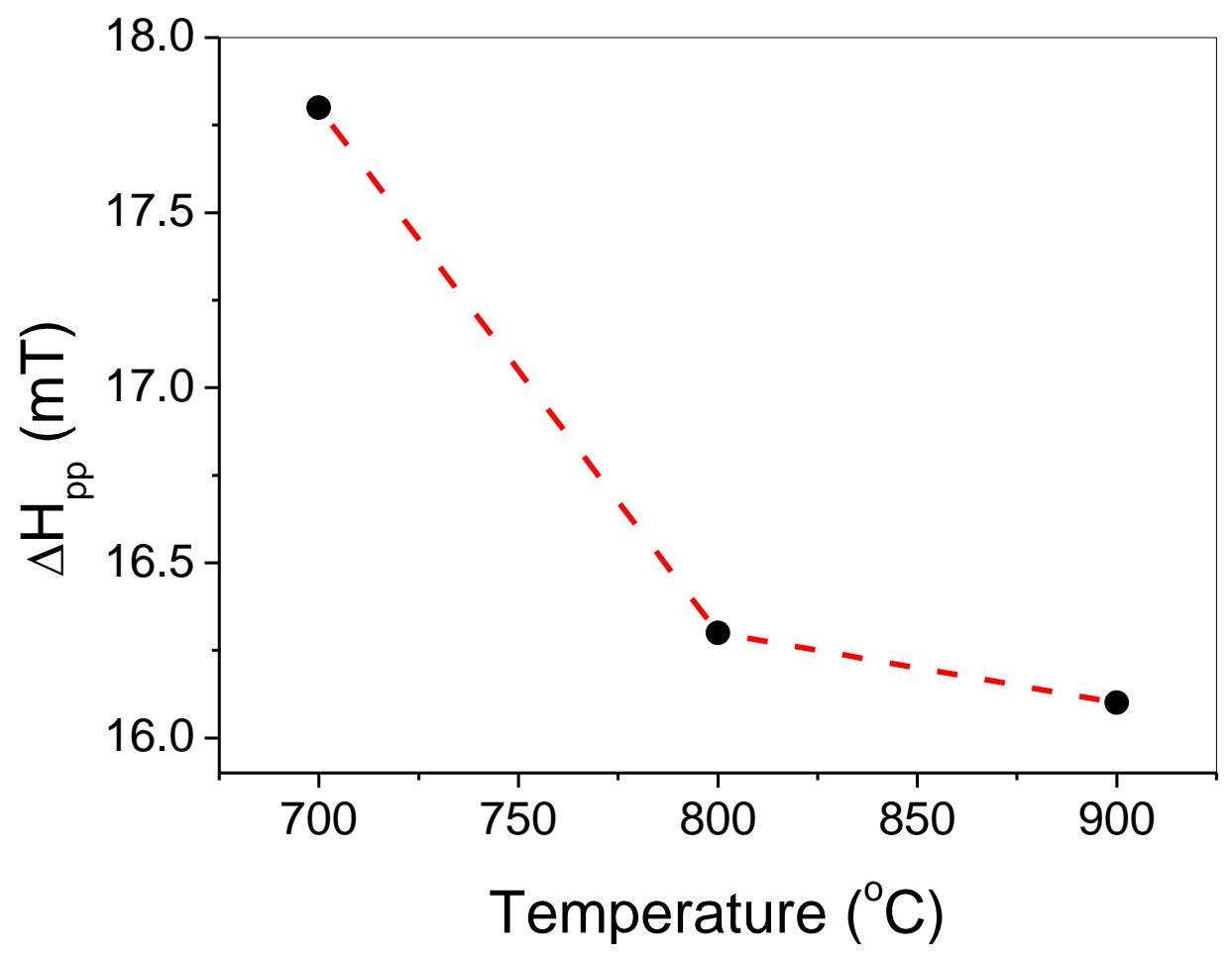

Figure S16. The heat temperature treatment versus the peak-to-peak line at g 2.0. 
<smiles>O=P([O-])([O-])[O-]</smiles>

$\mathbf{Q}^{0}$<smiles>COP(=O)([O-])[O-]</smiles>

$\mathbf{Q}^{1}$<smiles>COP(=O)(OC)OC</smiles>

$\mathbf{Q}^{3}$<smiles>COP(=O)([O-])OC</smiles>

$\mathbf{Q}^{2}$

Scheme S2. Interaction modes of phosphate ions.

\section{S.3. Methyl orange Fenton degradation}

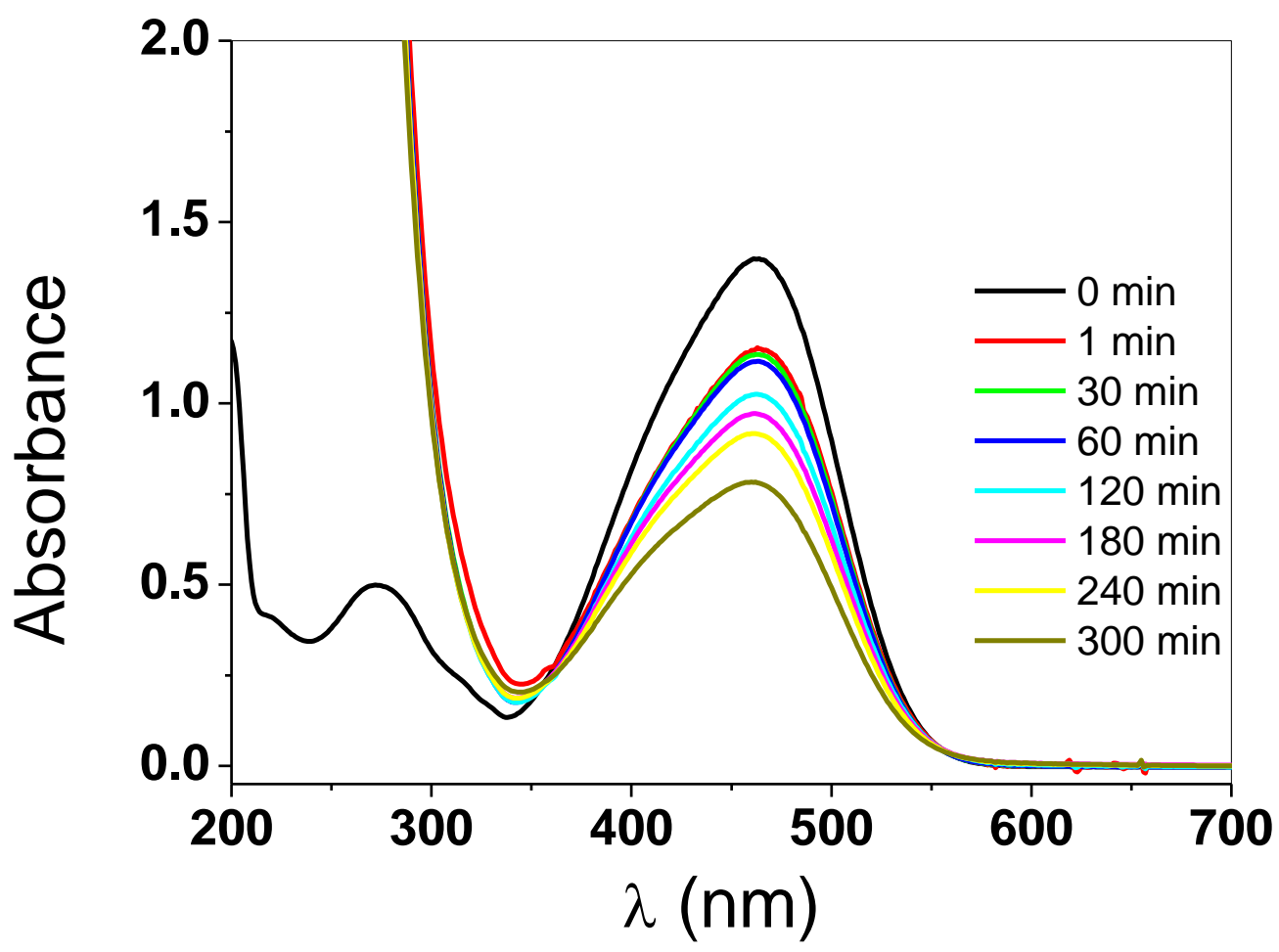

Figure S17. Electronic UV-VIS spectra of the methyl orange $\left(4.7 \times 10^{-5} \mathrm{~mol} \mathrm{~L}^{-1}\right)$ decolourization at 25 ${ }^{\circ} \mathrm{C}$ catalyzed by $10 \mathrm{mg}$ of ${ }^{\mathbf{B T}} \mathbf{F e} \mathbf{9 0 0}$.

$$
\mathrm{Fe}^{2+}+\mathrm{H}_{2} \mathrm{O}_{2} \rightarrow \mathrm{Fe}^{3+}+\mathrm{OH}^{-}+\cdot \mathrm{OH} \quad k_{1}=40-80 \mathrm{~L} \mathrm{~mol}^{-1} \mathrm{~s}^{-1}
$$




$$
\begin{array}{ll}
\mathrm{Fe}^{3+}+\mathrm{H}_{2} \mathrm{O}_{2} \rightarrow \mathrm{Fe}^{3+}+\cdot \mathrm{O}_{2} \mathrm{H} / \cdot \mathrm{O}_{2}^{-}+\mathrm{H}^{+} & k_{2}=0.01 \mathrm{~L} \mathrm{~mol}^{-1} \mathrm{~s}^{-1} \\
\mathrm{Fe}^{3+}+\cdot \mathrm{O}_{2}^{-} \rightarrow \mathrm{Fe}^{2+}+\mathrm{O}_{2} & k_{3}=1.4 \times 10^{5} \mathrm{~L} \mathrm{~mol}^{-1} \mathrm{~s}^{-1} \\
\mathrm{Fe}^{3+}+\cdot \mathrm{O}_{2} \mathrm{H} \rightarrow \mathrm{Fe}^{2+}+\mathrm{O}_{2}+\mathrm{H}^{+} & k_{4}=(0.33-2.1) \times 10^{6} \mathrm{~L} \mathrm{~mol}^{-1} \mathrm{~s}^{-1}
\end{array}
$$

[Q. Ouyang, F. Kou, N. Zhang, J. Lian, G. Tu, Z. Fang. Tea polyphenols promote Fenton-like reaction: pH self-driving chelation andreduction mechanism. Chem. Eng. J. 366 (2019) 514-522. https://doi.org/10.1016/j.cej.2019.02.078.] 